\title{
Future of electrochemistry in light of history and the present conditions
}

\author{
György Inzelt ${ }^{1}$
}

Received: 26 March 2020 / Revised: 26 March 2020 / Accepted: 29 March 2020 / Published online: 15 April 2020

(C) The Author(s) 2020

\section{General thoughts}

We may agree with the saying which is attributable to Niels Bohr who said: "It is difficult to make predictions, especially about the future." Nevertheless, the past can give ideas in this respect and the present circumstances set the course. However, the great breakthroughs cannot be predicted.

Without any exaggeration, we may declare that electrochemistry has played, plays, and will play an important role in the scientific and technological advancement, and consequently the quality of life of the people. We cannot imagine the everyday life without electricity. We have had electric current for 220 years since Volta constructed his pile. The year 1800 was the birth of electrochemistry because beside the production of the first electrochemical power source, electrolysis experiments were also executed.

Nowadays, I see some problem concerning the desired ratio between the fundamental and applied research. I agree that people are happy with small batteries in their cellular phone or in their pacemaker. It is also good that the research is directed to pollution control. The easy monitoring of glucose level in blood is also a real success. These are important achievements, and the production of things that make the life better is the ultimate goal of the science. Unfortunately, it is often forgotten that all these successes have started decades or even centuries earlier when a researcher discovered a new material or a novel property of matter. Afterwards, during an extended period of time, others clarified the theoretical basis which gave a new impetus, and many discoveries eventually lead to the new product which usually will be improved again and again for decades. The problem is that if the fundamental research

György Inzelt

inzeltgy@caesar.elte.hu

1 Department of Physical Chemistry, Institute of Chemistry, Eötvös Loránd University, Pázmány Péter sétány 1/A, Budapest 1117, Hungary would not be financed or financed properly, the development of science and consequently that of the technology will stop or at least will slow down. The decision makers want an immediate success for the money of the taxpayers. The applied research and especially the innovation phase needing the capital also for buildings and machines want orders of magnitude higher money than the grant for some thousand researchers at the universities and institutes.

The support of the basic research is not a wasted money, and it underlies the future. I would like to draw the attention to another important point: it is the proper education. The wellprepared and competent researchers are essential for the progress in the future. It is true in all cases, i.e., independently whether we are talking about basic or applied research, or even serendipity. The curiosity of scientists, the intuition, or the fantasy are of the utmost importance, however, the researchers need a solid knowledge, as well. "They have made up the solution of something they knew about, said Poirot."

\section{About the road to the discovery}

Let me illustrate my view using several examples. Two actual examples are the history of the achievements in electrochemistry that deserved the Nobel Prize in the twenty-first century. Because the conducting polymers have been the object of my research for decades, I intend to elaborate this area in a little more detail.

The story of the Li-ion batteries has started more than 200 years ago. The steps were as follows. In 1817, J. A. Arfvedson discovered Li in petalite. H. Davy produced the metal by using melt electrolysis (1818). Several researchers including R. W. Bunsen clarified its chemical properties in the nineteenth century. In 1913, G. N. Lewis determined the standard potential of $\mathrm{Li}^{+} / \mathrm{Li}$ system by measuring dilute amalgams of Li (Those are still the best values. Nowadays, only a few researchers work on the determination of fundamental quantities. It is difficult to have support for such enterprises.) $\mathrm{Li}$ 
batteries appeared in the 1960s, one of the most successful was the $\mathrm{Li} \mid \mathrm{I}_{2}$ - PVP battery invented by W. Greatbatch for peacemakers. In 2019, the Nobel Committee has chosen three outstanding scientists for their role in the development of Li-ion batteries (https://www.nobelprize.org/prizes/chemistry/2019/ press-release/) $[1,2]$. In the 1970s, Stanley Whittingham discovered that titanium disulfide cathode in a lithium battery can intercalate lithium ions. In 1979-1980, John B. Goodenough demonstrated that cobalt oxide with intercalated lithium ions can produce rather high potential. This was an important breakthrough and eventually led to powerful batteries. The anode was partially made from metallic lithium; however, the use of metallic lithium as an anode had safety problems. Akira Yoshino created the first commercially viable lithium-ion battery in 1985 . Rather than using reactive lithium in the anode, he applied a carbon material that can intercalate lithium ions. He used Li-salt dissolved in organic solvent. The first Li batteries entered in the market in 1991. However, the real success story of these batteries spanning from the use in the portable electronics to the long-range electric cars has been started in the twenty-first century.

We should not forget the contribution of many other researchers since W. Rüdorff started to investigate the intercalation processes among others that of lithium ions to graphite in the late 1930s, or the solvent used was developed first by W. S. Harris and was described in his Ph.D. thesis (supervisor: Charles C. Tobias) in 1958. The development of polymer electrolytes and the suitable salts has to be also emphasized [2, 3].

The other story began in the 1970s, when, somewhat surprisingly, a new class of polymers possessing high electronic conductivity (electronically conducting polymers) in the partially oxidized (or, less frequently, in the reduced) state was discovered. Three collaborating scientists, Alan J. Heeger, Alan G. MacDiarmid, and Hideki Shirakawa, played a major role in this breakthrough, and they received the Nobel Prize in Chemistry in 2000 "for the discovery and development of electronically conductive polymers" [4-9].

The twentieth century produced the polymers without those one cannot imagine the everyday life. The discovery or in a certain extent rediscovery of polymers possessing variable electronic conductivity launched a new field of research about 40 years ago. Conducting (conductive) polymers have conquered a very wide field of electrochemical research, which led to numerous new applications in very different areas such as the variation of the conductivity in electronic devices including thin film transistors and insulated gate field effect transistors or in gas sensors; the color change in electrochromic display devices or in smart windows, the electroluminescence in light emitting devices, the swellingdeswelling accompanying the charging-discharging processes in artificial muscles, the charge storage capacity in energy technologies (batteries, supercapacitors), and corrosion protection. One of the most notable features of the conducting polymers is the potential-dependent variation of their charging state. It can be applied e.g., to remove ionic species from waste water via stripping, and release those by changing the charging state of the polymer layer. Similarly, it is possible to regulate the dosage of different medicines even in vivo. Conducting polymers with combination with other compounds (embedded enzymes, polyelectrolytes etc.) can be used for specific purposes, e.g., in biosensors.

Nanocomposites, hybrid materials based on conducting polymers certainly become and will be important materials in the future. There is a high expectation concerning electroconducting nanomaterials such as nanofibers, nanorods, and other nanostructures based on the supramolecular self-assembly of conducting polymers, e.g., in the enhancement of the photoluminescence efficiency by utilization of the energy and charge transfer effect in surface resonance coupling. Manipulation of the microstructures of polymers may improve the performances of both the polymer-based transistors and electrochemical cells. There will be tasks for the chemists, electrochemists in the production, and characterization of new materials, for the theoreticians to explain the phenomena observed or will be observed and to predict new opportunities, and also engineers to give a final form of the devices. The conducting polymers are relatively cheap materials; however, the specially improved properties can give a further boost concerning the mass production, which makes the products much less expensive. For instance, making ink from conducting polymers opens up new horizons for printing sensors, electronic circuits, solar cells, light emitting displays etc.

Supercapacitors have become perhaps the most popular topic as far as the number of the submitted papers is taken into account. Usually composites of conducting polymers with inorganic materials including new materials such as carbon nanoparticles, nanofibers, graphene, and graphene oxides have been prepared and tested. The combinations of conducting polymers with these materials and other compounds (e.g., metal oxides) with high surface area and mechanical stability seem to be a plausible choice.

All these achievements trace back to the last two centuries. In short, Dr. Henry Letheby (1862) observed that a bluishgreen precipitate was formed at the anode during electrolysis of aniline, which became colorless when it was reduced and regained its blue color when it was oxidized again. F. F. Runge (1834) and C. J. Fritzsche (1840), who isolated aniline, also observed the appearance of a blue color during the oxidation of aniline in acidic media. T. Yasui (1935) suggested a reaction scheme for the electrooxidation of aniline at a carbon electrode. Khomutov and Gorbachev (1950) discovered the autocatalytic nature of the electrooxidation of aniline. In 1962, Mohilner, Adams, and Argersinger reinvestigated the mechanism of the electrooxidation of aniline in aqueous sulfuric acid solution at a platinum electrode.

The first real breakthrough came in 1967, when Buvet delivered a lecture at the 18th Meeting of CITCE (later ISE), and 
this presentation appeared a year later in Electrochimica Acta [10]. Here we cite the first sentence of this paper, which speaks for itself: "Polyanilines are particularly representative materials in the field of organic protolytic-polyconjugated macromolecular semiconductors, because of their constitution and chemical properties." They also established that polyanilines "also have redox properties," and that "the conductivity appears to be electronic." It was also shown that "polyanilines are also ion-exchangers." Finally, they proposed that "polyanilines... can be utilized for making accumulators with organic compounds."

Diaz and Logan (1980) initiated the research of the polymer film electrodes based on polyaniline, which continues even today. The polyaniline saga alone provides an excellent illustration of the development of science. In fact, the discovery in the 1970s of polyacetylene — which had no practical importance but helped to arouse the interest of researchers and public alike-was another episode in the history of conducting polymers. Thus, these materials have a long history and - perhaps without any exaggeration — a bright future.

\section{Milestones in the industrial processes}

There are two examples from the many inventions that have revolutionized industrial electrolysis technologies and electrosyntheses processes. The first that I selected is the development of the dimensionally stable anodes $(\mathrm{H}$. Beer, V. de Nora, S. Trasatti) in the chlor-alkali industry. Another one is the cathodic hydrocoupling of acrylonitrile, i.e., the electrosynthesis of adiponitrile (Baizer found the proper electrolyte in 1960). All of these very profitable findings have started by laboratory experiments previously. It is easy to foresee that the successful application of electrochemical processes will continue also in the next decades with special emphasis on the environmental protection.

\section{How can we miss a discovery?}

It has happened many times that a new material was prepared electrochemically; however, the discovery was missed because there were no appropriate methods of investigation. For instance, Henning Lund described such a case [11]. They investigated the electroreduction of graphite at a mercury electrode in DMF with tetraoctylammonium bromide. Most likely, they obtained graphene but they could not study the product due to the lack of equipment at that time. In addition, they did not think that graphene would be of interest (for which a Nobel Prize in physics was awarded in 2010).

It was in the 1970s that one of my colleagues investigated the electrooxidation of aromatic amines. He always complained that during the electrolysis films - usually colored - films were formed on the platinum surface. Therefore, he had to clean the platinum plate very carefully before the next experiment which was a rather tedious work. These films aroused my interest, and I wanted to study these films which were strongly bounded to the metal. However, in the 1970s, I had no proper potentiostat, function generator, and $\mathrm{X}-\mathrm{Y}$ recorder to execute cyclic voltammetric experiments. We used galvanostatic and later potentiostatic techniques, and measured the current or the potential, as well as measured or calculated the amount of charge. Furthermore, the elder professors in Hungary did not like such methods like cyclic voltammetry; they insisted to the steady-state investigations. I could start to produce and characterize such surface layers 10 years later when the study on the polymer modified electrodes has already started.

\section{Further expected studies and developments in the near future}

The renaissance of fuel cells and hydrogen economy is already here. This story has started in 1838 by the pioneering findings of Christian Friedrich Schönbein and William Grove, and continued with the works of Francis Thomas Bacon in the twentieth century.

I expect substantial progress in the old topics which have been extensively cultivated in the second half of the last century. One of these issues is the better understanding of the electric double layer structure and its role. We have several methods to investigate the surface structure at atomic level and also the composition of the electrolyte. This is one of the areas where the advanced computing techniques could be successfully utilized. Another one is the better understanding of the electron transfer at the interface and also in solution. In the electrochemistry textbooks, one may find the Nobel Prizes of Henry Taube (1983) and Rudolph Marcus (1992) but not too much afterwards.

Photoelectrochemistry or semiconductor electrochemistry that has started about 50 years ago (Heinz Gerischer) or bioelectrochemistry (which traces back to Luigi Galvani) including biosensors and microbial bioelectrochemistry is still in progress.

The technical development has played a very important role on the development of electrochemistry in the last 50 years, and will play similar role in the future. Fifty years ago, a potentiostat and an $\mathrm{X}-\mathrm{Y}$ recorder were the modern equipments to study electrode kinetics. An impedance measurement was a labor-intensive endeavor. Nowadays, we routinely use computer assisted-potentiostats, frequency analyzers, scanning microscopies, nanobalance, and other combined techniques.

There is still lot of room for new discoveries in electrochemistry, take the advice of Michael Faraday: "work, finish, publish" (whatever publishing will mean years from now). 
Funding information Open access funding provided by Eötvös Loránd University (ELTE).

Open Access This article is licensed under a Creative Commons Attribution 4.0 International License, which permits use, sharing, adaptation, distribution and reproduction in any medium or format, as long as you give appropriate credit to the original author(s) and the source, provide a link to the Creative Commons licence, and indicate if changes were made. The images or other third party material in this article are included in the article's Creative Commons licence, unless indicated otherwise in a credit line to the material. If material is not included in the article's Creative Commons licence and your intended use is not permitted by statutory regulation or exceeds the permitted use, you will need to obtain permission directly from the copyright holder. To view a copy of this licence, visit http://creativecommons.org/licenses/by/4.0/.

\section{References}

1. Yoshino A (2012) The birth of the lithium-ion battery. Angew Chemie Int Ed 51:5798-5800

2. Scrosati B (2011) History of lithium batteries. J Solid State Electrochem 15:1623-1630
3. Arya A, Sharma AL (2017) Polymer electrolytes for lithium ion batteries: a critical study. Ionics 23:497-540

4. Shirakawa $H$ (2001) The discovery of polyacetylene film: the dawning of an era of conducting polymers. Angew Chem Int Ed 40(14):2574-2580

5. MacDiarmid AG (2001) A novel role for organic polymers. Angew Chem Int Ed 40(14):2581-2590

6. Heeger AJ (2001) Semiconducting and metallic polymers: the fourth generation of polymeric materials. Angew Chem Int Ed 40: 2591-1611

7. Inzelt G (2017) Recent advances in the field of conducting polymers. J Solid State Electrochem 21:1965-1975

8. Inzelt G (2011) Rise and rise of conducting polymers. J Solid State Electrochem 15:1711-1718

9. Inzelt G (2012) Conducting polymers - a new era in electrochemistry. In: Scholz F (ed) Monographs in electrochemistry, 2nd edn. Springer, Heidelberg Berlin

10. de Surville R, Josefowicz M, Yu LT, Perichon J, Buvet R (1968) Electrochim Acta 13:1451-1458

11. Lund H (2011) From synthetic organic chemistry to electrochemistry. J Solid State Electrochem 15:1733-1751

Publisher's note Springer Nature remains neutral with regard to jurisdictional claims in published maps and institutional affiliations. 